\title{
A Chemoselective Approach to Grafting Biodegradable Polyesters
}

Ikuo Taniguchi ${ }^{\dagger}$, Anne M. Mayes*, Eugene W. L. Chan ${ }^{\dagger}$, Linda G. Griffith

\section{Supporting Information}

Size exclusion chromatography (SEC)

SEC was performed on a Viscotek GPCmax VE2001 (Viscotek, TX) equipped with a Viscotek VE 3580

RI detector (Viscotek). and Styragel HR4 gel columns T92881B 12, W21721G 024, and T53311A 08

(Waters, MA) in series, and using tetrahydrofuran at $25^{\circ} \mathrm{C}$ as an eluent at a flow rate of $1.0 \mathrm{~mL} / \mathrm{min}$.

Molecular weights were calibrated to polystyrene standards. Figure A shows the SEC traces for the separate reactants (fine and plain lines) and products of the reaction (bold line). The polymer fraction of the reaction mixture is nearly identical to the parent polymer, suggesting that no chain scission occurred during the coupling reaction. 


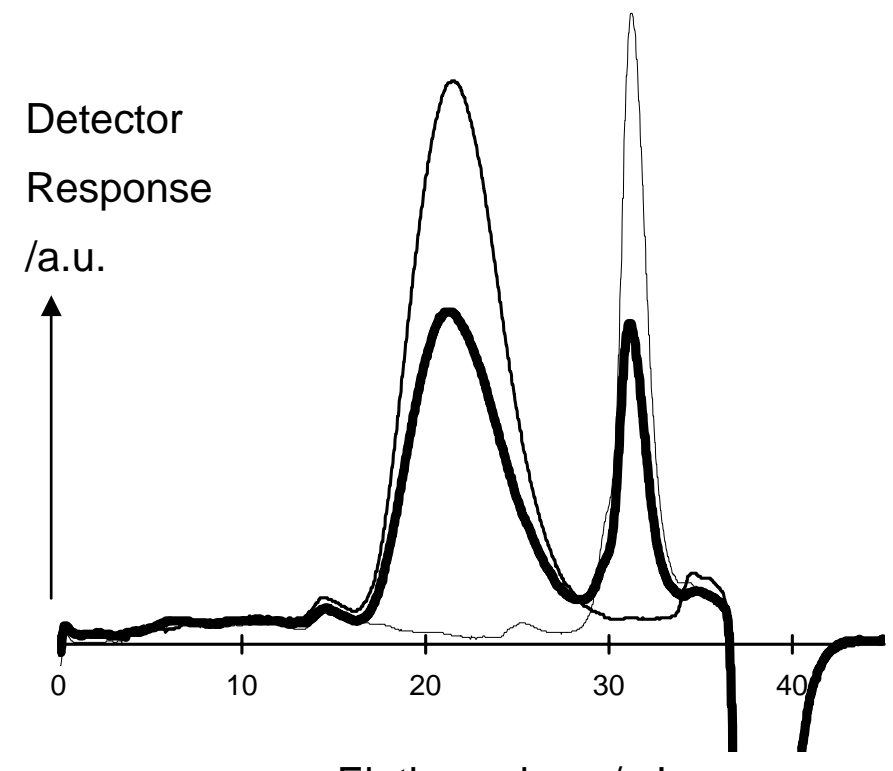

Elution volume/mL

Figure A. Elution profiles of PCL backbone (plain line), aminooxy terminated methoxy PEO (MW: 2

$\mathrm{kg} / \mathrm{mol}$ ) (fine line) and the reaction mixture of PCL backbone and the PEO (bold line). $M_{\mathrm{w}}$ values of the polymer fractions (plain and bold lines) are 233 and $237 \mathrm{~kg} / \mathrm{mol}$, respectively.

\footnotetext{
${ }^{13}$ C NMR spectra
}

The ${ }^{13} \mathrm{C}$ NMR spectra were recorded in $\mathrm{CDCl}_{3}$ at $25{ }^{\circ} \mathrm{C}$ using a Bruker AM400 apparatus operating at 100 MHz and a sample concentration was $60 \mathrm{mg} / \mathrm{mL}$. A pre-grafted PCL $\left(M_{\mathrm{w}}: 30 \mathrm{~kg} / \mathrm{mol} ; M_{\mathrm{w}} / M_{\mathrm{n}}: 1.3\right)$ was reacted with aminooxy methoxy triethylene glycol in chloroform at $40{ }^{\circ} \mathrm{C}$ for one day. The stoichiometry of ketones to aminooxy groups was 1:10, and complete conversion was achieved under this condition. The resulting PCL-g-PEO was isolated by reprecipitation in methanol. A PEO content of 
$24 \mathrm{wt} \%$ was obtained. The expanded ${ }^{13} \mathrm{C}$ NMR spectra are shown in Figure B. The peak of the ketone carbon at 206 ppm disappeared while two peaks of the oxime carbon at 155 ppm emerged.

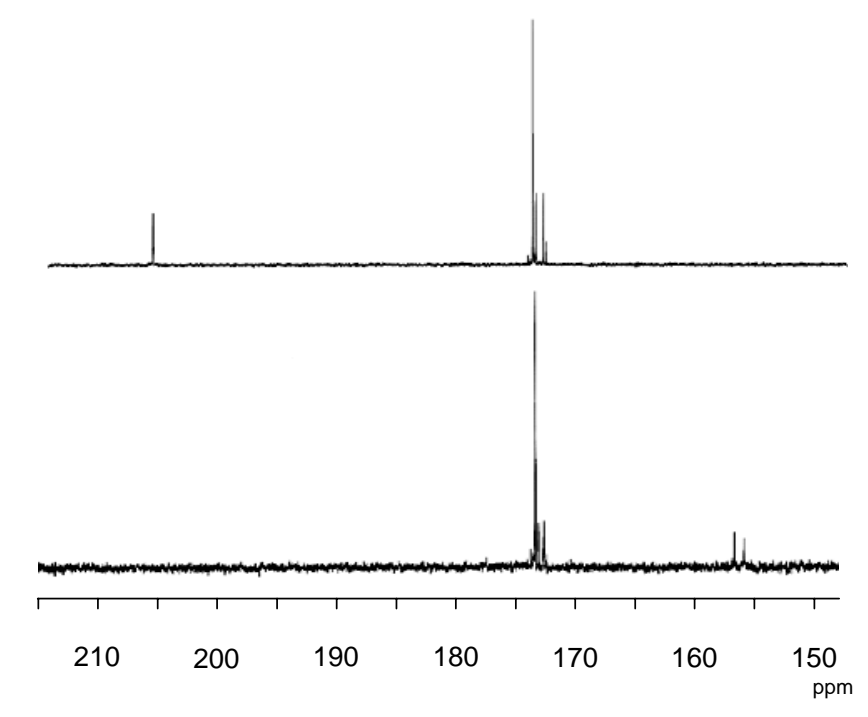

Figure B. Expanded ${ }^{13} \mathrm{C}$ NMR spectra of PCL backbone (upper) and PCL-g-PEO after complete coupling with aminooxy triethylene glycol (bottom).

Fourier transfer-infrared spectroscopy (FT-IR)

FT-IR of the pre-grafted PCL and the grafted PCL was also measured on a Magna-IR 860 spectrometer (Thermo Electron Corporation, MA). The samples used were the same mentioned above and were cast on a $\mathrm{NaCl}$ plate and dried prior to the measurement. The peak of $\mathrm{C}=\mathrm{O}$ stretching at $1716 \mathrm{~cm}^{-1}$ decreased whereas a peak at $1640 \mathrm{~cm}^{-1}$ emerged, which can be assigned to the stretching of the $\mathrm{C}=\mathrm{N}$ bond. 


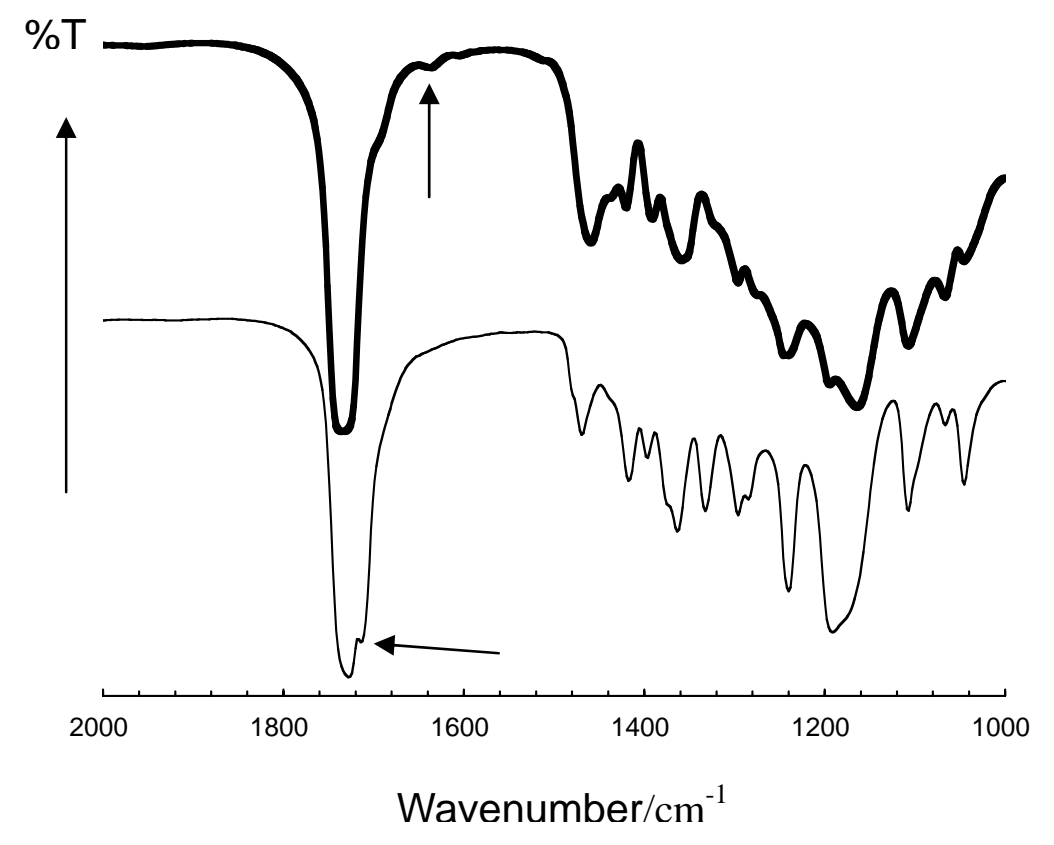

Figure C. Expanded FT-IR spectra of PCL backbone (plain line) and PCL-g-PEO after complete coupling with aminooxy triethylene glycol (bold line). $\quad M_{\mathrm{w}}$ and $M_{\mathrm{w}} / M_{\mathrm{n}}$ of the pre-grafted PCL were 30 $\mathrm{kg} / \mathrm{mol}$ and 1.3 , respectively. The PEO content of the grafted polymer was $24 \mathrm{wt} \%$.

Thermal stability of PCL-g-PEO

Thermal stability of the pre-grafted and the grafted polymer was studied using a TGA 7

thermogravimetric analyzer (Perkin Elmer, MA). Thermal gravimetric analysis (TGA) was performed under a $\mathrm{N}_{2}$ atmosphere with a heating rate of $20^{\circ} \mathrm{C} / \mathrm{min}$. PCL-g-PEO (bold line) demonstrated higher 
thermal stability than the pre-grafted PCL (plain line), showing $0.6 \%$ weight decrease at $200{ }^{\circ} \mathrm{C}$, and $5 \%$ at $290{ }^{\circ} \mathrm{C}$, compared to $5 \%$ at $260{ }^{\circ} \mathrm{C}$ for the parent polyester. TGA results suggest sufficient thermal stability of the comb copolymer for melt processing.

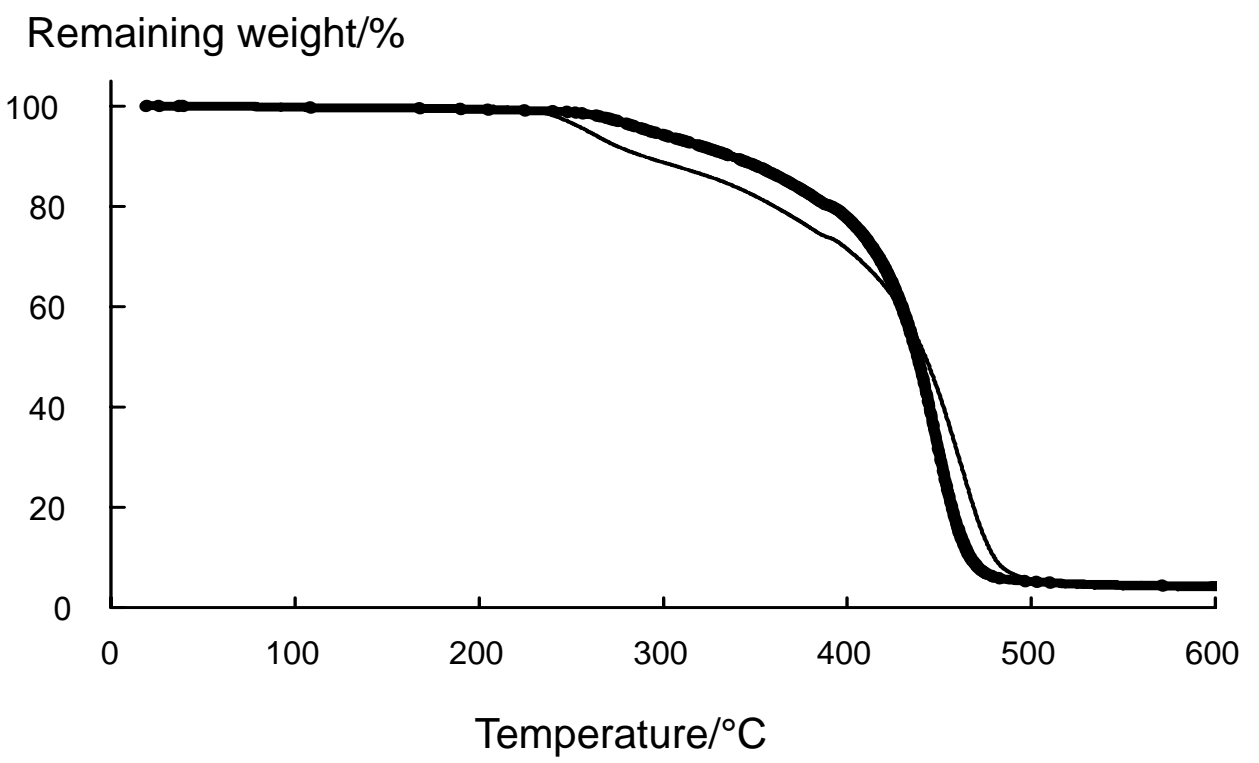

Figure D. TGA of PCL- $g$-PEO under $\mathrm{N}_{2}$ atmosphere. $\quad M_{\mathrm{w}}$ and $M_{\mathrm{w}} / M_{\mathrm{n}}$ of the pre-grafted PCL were 30 $\mathrm{kg} / \mathrm{mol}$ and 1.3, respectively. The PEO (triethylene glycol) content of the grafted polymer was $24 \mathrm{wt} \%$.

The heating rate was $20^{\circ} \mathrm{C} / \mathrm{min}$. 